\title{
CrimRxiv
}

\section{Confirmation bias in}

simulated CSA interviews:

How abuse assumption

influences interviewing

and decision-making

processes?

Yikan Zhang, Aleksandr Segal, Francesco Pompedda, Shumpei Haginoya, Pekka Santtila

Published on: Mar 01, 2022

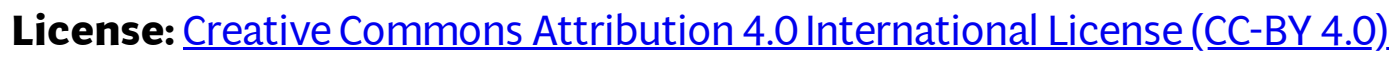


